\title{
OBITUARY
}

\section{Dr Igor Klatzo (1916-2007)}

It is a great sadness to announce the death of Dr Igor Klatzo, former Chief of Laboratory of Neuropathology and Neuroanatomical Sciences, National Institute of Neurological Disorders and Stroke, National Institute of Health (NINDS, NIH), Bethesda, Maryland, USA. After several years of suffering from metastatic cancer, Dr Klatzo died peacefully on May 5, 2007 in Gaithersburg, Maryland, USA, surrounded by his family.

Igor Klatzo was born on October 9, 1916 in St. Petersburg, Russia. His career in medicine began in Neustadt, Germany in 1946, where he was a Research Associate at the Brain Research Institute. He received his M.D. from the University of Freiburg, Germany in 1947, and M.Sc. from McGill University, Montreal, Canada in 1952.

He was appointed Chief of Laboratory of Neuropathology and Neuroanatomical Sciences at NINDS, NIH in 1967 where he had a distinguished academic career in neuropathology. This included the first pathological report of Kuru and the famous classification of brain edema. During his appointment to NIH, Dr Klatzo was a great teacher and leader to many scientists/clinicians visiting his laboratory. This included many visiting fellows from Japan performing experimental research on cerebral ischemia. After his retirement from the NIH in 1993, his academic activity focused on publishing a biography on Cecil and Oskar Vogt, proposers of the Pathoclisis Theory, and founders of the Brain Research Institute in Neustadt, Germany, where Dr Klatzo started his academic career.

Dr Igor Klatzo was a great neuroscientist who always enjoyed the beauty of the nature and the beauty of our lives.

Klatzo I, Gajdusek DC, Zigas V. Pathology of Kuru. Lab Invest 1959; 8: 799-847.
Klatzo I. Presidential address: neuropathological aspects of brain edema. J Neuropathol Exp Neurol 1965; 26: $1-13$.

Klatzo I, Seitelberger F, eds. Brain Edema. New York, Berlin, Heidelberg: Springer Verlag, 1967.

Klatzo I. Cecile and Oskar Vogt: the visionaries of modern neuroscience. Acta Neurochir Suppl 2002; 80.

Toshihiko Kuroiwa, MD Visiting Associate Professor, University of Michigan Health System

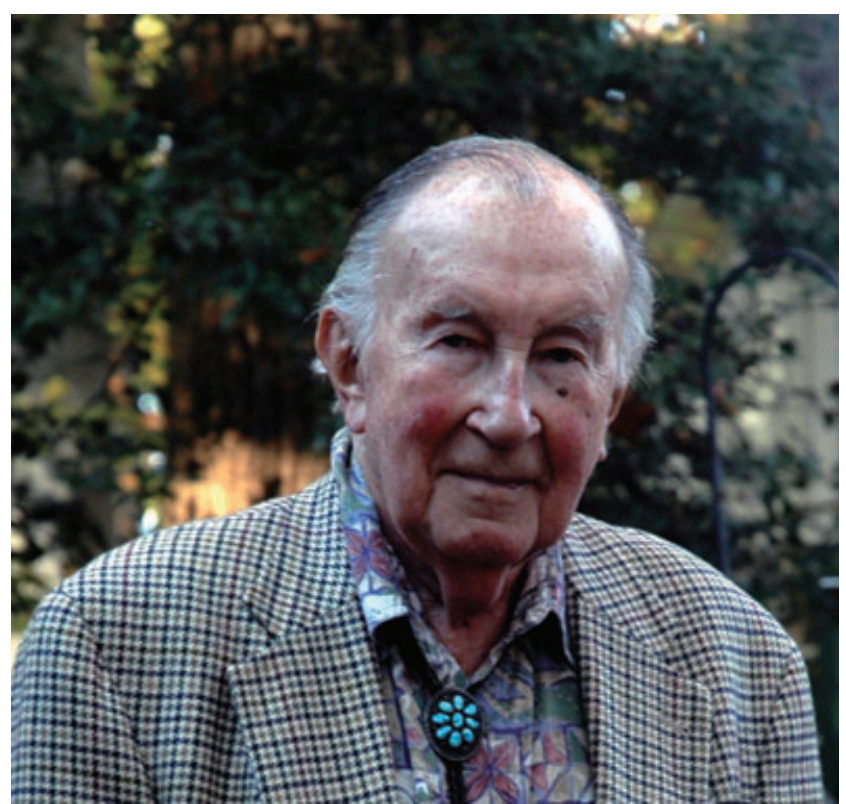

Fig. 1 Dr Igor Klatzo. 